\title{
A double-blind, placebo-controlled study of the short term effects of a spring water supplemented with magnesium bicarbonate on acid/base balance, bone metabolism and cardiovascular risk factors in postmenopausal women
}

Richard O Day ${ }^{1}$, Winston Liauw ${ }^{2}$, Lynette MR Tozer ${ }^{3 *}$, Patrick McElduff ${ }^{3}$, Russell J Beckett ${ }^{4}$, Kenneth M Williams ${ }^{1}$

\begin{abstract}
Background: A number of health benefits including improvements in acid/base balance, bone metabolism, and cardiovascular risk factors have been attributed to the intake of magnesium rich alkaline mineral water. This study was designed to investigate the effects of the regular consumption of magnesium bicarbonate supplemented spring water on $\mathrm{pH}$, biochemical parameters of bone metabolism, lipid profile and blood pressure in postmenopausal women.

Findings: In this double-blind, placebo-controlled, parallel-group, study, 67 postmenopausal women were randomised to receive between $1500 \mathrm{~mL}$ and $1800 \mathrm{~mL}$ daily of magnesium bicarbonate supplemented spring water (650 mg/L bicarbonate, $120 \mathrm{mg} / \mathrm{L}$ magnesium, pH 8.3-8.5) (supplemented water group) or spring water without supplements (control water group) over 84 days. Over this period biomarkers of bone turnover (serum parathyroid hormone (PTH), 1,25-dihydroxyvitamin D, osteocalcin, urinary telopeptides and hydroxyproline), serum lipids (total cholesterol, HDL-cholesterol, LDL-cholesterol and triglycerides), venous and urinary pH were measured together with measurements of standard biochemistry, haematology and urine examinations. Serum magnesium concentrations and urinary $\mathrm{pH}$ in subjects consuming the magnesium bicarbonate supplemented water increased significantly at Day 84 compared to subjects consuming the spring water control (magnesium - $\mathrm{p}=0.03 ; \mathrm{pH}-\mathrm{p}=0.018$ ). The consumption of spring water led to a trend for an increase in parathyroid hormone (PTH) concentrations while the PTH concentrations remained stable with the intake of the supplemented spring water. However there were no significant effects of magnesium bicarbonate supplementation in changes to biomarkers of bone mineral metabolism (n-telopeptides, hydroxyproline, osteocalcin and 1,25-dihydroxyvitamin D) or serum lipids or blood pressure in postmenopausal women from Day 0 to Day 84.
\end{abstract}

Conclusions: Short term regular ingestion of magnesium bicarbonate supplemented water provides a source of orally available magnesium. Long term clinical studies are required to investigate any health benefits.

Trial registration: ACTRN12609000863235

\footnotetext{
* Correspondence: lyntozer@datapharm.com.au

${ }^{3}$ Datapharm Australia Pty Ltd, Drummoyne NSW 2047, Australia
} 


\section{Background}

Epidemiological observational studies have found an inverse association between the incidence of, and mortality from, cardiovascular disease and increased drinking of water containing mineral salts of calcium and magnesium [1-3]; particularly in women [4]. In case control studies, drinking water with greater than $8 \mathrm{mg} / \mathrm{L}$ of magnesium was associated with lower risk of death from myocardial infarction [4-6]. A recent meta-analysis of such epidemiology studies further supported the inverse association between magnesium levels in drinking water and cardiovascular mortality [7]. A lower risk of myocardial infarction among men drinking water with magnesium and bicarbonate with concentrations of greater than $110 \mathrm{mg} /$ $\mathrm{L}$ compared to those who consumed magnesium in water with minimal bicarbonate was imputed from epidemiological studies in Sweden [6,8]. It is possible, therefore, that any beneficial effects from the magnesium content of waters may be enhanced by bicarbonate.

Clinical studies have reported that bicarbonate from mineral waters lowers bone resorption [reviewed in [9]] and may reduce cardiovascular risk as evidenced by associated decreases in early markers of atherosclerosis in healthy postmenopausal women [10]. Western diets generally have a high dietary acid load and are associated with in a low intake of minerals such as magnesium, calcium and potassium. Such diets can induce a chronic, low-level, metabolic acidosis [11-13]. The degree of acidosis also increases with age and, therefore, it has been postulated that acidosis may be associated with some of the diseases of aging [12]. Drinking water containing bicarbonate may represent a means of regulating acid base balance.

Magnesium is a cofactor for approximately 300 enzymes. About $50 \%$ of magnesium in the body resides in bone where it is directly involved in calcium and bone homeostasis. Magnesium affects the function of the parathyroid glands [14] where it acts as an agonist at the calcium-sensing receptors and, like calcium, can decrease parathyroid hormone (PTH) secretion [15]. Low magnesium status has been associated with cardiovascular disease, hypertension, diabetes [16] and osteoporosis [17]. Magnesium supplementation has been linked with suppression of bone turnover [18] and improvements in lipid profile and blood pressure $[19,20]$.

This randomised double-blind, placebo-controlled study was conducted in postmenopausal women to investigate whether the short term regular ingestion of spring water supplemented with magnesium bicarbonate could contribute to the intake of magnesium and influence acid base balance, metabolic parameters of bone turnover and cardiovascular risk factors (blood pressure and serum lipids).

\section{Methods}

A randomised, double-blind, placebo-controlled, parallel-arm study comparing the daily intake of $1500 \mathrm{~mL}$ $1800 \mathrm{~mL}$ of magnesium bicarbonate supplemented spring water with non supplemented spring water (placebo) was undertaken in postmenopausal women, while on their usual diet, over an 84 day period. The study was conducted from 31 August 2005 to 3 November 2006 and approved by the St Vincent's Hospital Human Research Ethics Committee.

\section{Subjects}

Ninety-one subjects attended the Clinical Trials Centre for screening for eligibility. All screened subjects provided written informed consent to participate in the study prior to commencement of screening procedures.

Only postmenopausal subjects aged $50-70$ years and with a body mass index (BMI) $20-35 \mathrm{~kg} / \mathrm{m}^{2}$ were eligible. Subjects were excluded if physical and mental health status, including laboratory abnormalities, indicated serious or chronic illness (abnormal liver function tests (LFTs) or electrolytes, creatinine clearance $<60$ $\mathrm{mL} / \mathrm{min}$, haemoglobin $<10 \mathrm{~g} / \mathrm{L}$ ), if they were intolerant to magnesium-containing products, taking certain medications (antacids other than proton pump inhibitors or $\mathrm{H}_{2}$ agonists, diuretics, calcium or magnesium supplements) or planned medication changes. Subjects using hormone replacement therapy (HRT) were to have been on a stable dose for at least one month prior to screening and continue this dose through the study. Subjects on special diets (including vegan, weight loss or high protein), those with a history of frequent use of magnesium based laxatives and substance abuse (including nicotine) were excluded.

\section{Protocol - treatment}

Of the 91 screened, 23 failed to satisfy the entry criteria and one was excluded due to poor venous access. The remaining 67 postmenopausal women were randomised in a $1: 1$ ratio to receive between $1500 \mathrm{~mL}$ and $1800 \mathrm{~mL}$ daily of magnesium bicarbonate supplemented spring water $(650 \mathrm{mg} / \mathrm{L}$ bicarbonate, $120 \mathrm{mg} / \mathrm{L}$ magnesium, $\mathrm{pH}$ 8.3-8.5) (supplemented water group) or spring water without supplements (control water group) over three months (84 days). For those consuming the supplemented water, this volume resulted in a daily dose of 975 $1170 \mathrm{mg}$ bicarbonate and $180-216 \mathrm{mg}$ of magnesium. There was no bicarbonate and negligible amounts of magnesium $(<5 \mathrm{mg} / \mathrm{L})$ in the spring water given to the control group. Analysis of the spring water (control) was conducted by National Association of Testing Authorities (NATA) accredited (\#1884) SONIC 
HEALTHCARE laboratory NSW and the constituents are listed in Additional file 1.

The water was supplied in $600 \mathrm{~mL}$ identical bottles so that subjects were blinded to the type of water they received. Subjects were at liberty to choose the time at which they consumed the water and were discouraged from drinking the study product with meals. The water could be chilled but not heated to be used in beverages such as tea or coffee, or for cooking. All study water consumed was recorded by subjects in the drink diary and bottle caps returned at each study visit to evaluate compliance, where $100 \%$ compliance was defined as daily consumption of between $1500 \mathrm{~mL}$ and $1800 \mathrm{~mL}$ of water. Subjects were requested to maintain consistency of nutritional habits and lifestyle behaviours throughout the study period.

\section{Measurements}

Subjects were seen at Baseline and at Days 14, 42 and 84. Any changes in diet were noted. Blood and urine samples were collected at every visit to measure markers of bone turnover (PTH, 1,25-dihydroxyvitamin D and osteocalcin, urinary telopeptides, hydroxyproline) and $\mathrm{pH}$. Serum fasting lipids (total cholesterol, HDL, LDL, triglycerides), serum biochemistry (albumin, alkaline phosphatase, alanine amino transferase [ALT], aspartate amino transferase $[\mathrm{AST}]$, bicarbonate, total bilirubin, chloride, calcium, creatine kinase, creatinine, fasting glucose, lactate dehydrogenase [LDH], magnesium, potassium, sodium, total protein, urea and uric acid) and haematology were measured at each visit. Urine was collected for $24 \mathrm{~h}$ for the measurement of calcium, phosphate, creatinine and free cortisol concentrations and excretion. Physical examinations were performed; including blood pressure (supine and standing); body weight recorded and adverse event reports were elicited at each visit.

All biochemical, haematology and urinalysis testing was performed by NATA accredited (\#2115) Institute of Laboratory Medicine (SydPath) St Vincent's Hospital NSW.

\section{Statistics}

The change from Baseline (Day 0) to each study visit at Days 14, 42 and 84 was compared between treatment groups for all biochemical, blood lipid, blood pressure, $\mathrm{pH}$ measures, haematological, urinalysis and bone turnover markers. Tables and figures present the mean and standard deviation (SD) for each parameter at baseline and at each visit. Continuous measures were compared across treatments using independent, two-sample, unpaired $\mathrm{t}$-tests if the data were normally distributed, otherwise the Wilcoxon Rank Sum Test was used. Categorical measures were compared using Chi square or
Fisher's Exact test. No adjustments were made for multiple testing as this was an exploratory study and it is acknowledged that there is an increased risk of making Type I errors given the number of tests performed.

Repeated measures analyses of variance were performed for all outcome variables, incorporating all visits from baseline to Day 14, Day 42 and Day 84 together with treatment group as factors in the analysis. If the $\mathrm{p}$-value for the change in the variable was less than or equal to 0.10 then a generalised linear mixed model with a random intercept term (for subject) was fitted. The outcome in the model was the measure of interest at Days 0, 14, 42 and 84 and the model included the main effects of group and visit. The p-value from the test of the interaction between group and time was the result of interest and $\mathrm{p}<0.05$ was considered statistically significant.

\section{Results}

Sixty-seven eligible subjects received at least one dose of magnesium bicarbonate supplemented spring water $\{$ supplemented water group; $\mathrm{n}=34\}$ or one dose of spring water without supplement \{control group; $\mathrm{n}=$ $33\}$, had a valid baseline measurement and returned for at least one post-baseline visit. All analyses were carried out on this population which was identical to the safety population.

Mean (SD) age was 57 (4.4) years and 59 (5.5) years in the control and supplemented water groups, respectively. Body weight and BMI remained unchanged in both groups (Table 1) over the study period. Dietary habits in both groups were unchanged as assessed at each visit.

There were no significant group differences in all parameters measured at baseline (Day 0) (Tables 2, 3, 4, 5, Additional files 2, 3, 4, 5).

The most common pre-existing conditions in both groups were self-reported drug hypersensitivity, osteoarthritis and lipid disorders for which subjects used hypolipidaemics, anti-inflammatory and antirheumatic products and analgesics. The compliance rate was high in both groups $\{28(84.8 \%)$ in the control and 29 $(85.3 \%)$ and supplemented water groups $\}$ according to daily diary records. The $1500 \mathrm{~mL}-1800 \mathrm{~mL}$ of water volume was well tolerated by all subjects.

\section{Outcome Analyses}

There were no statistically significant differences in change between the supplemented water group and the water control group from baseline to Day 14, 42 and 84 in any of the measures of bone mineral turnover (n-telopeptides, hydroxyproline, osteocalcin and 1,25dihydroxyvitamin D) (Table 2, Additional file 2) or in cardiovascular parameters of serum lipid profile 
Table 1 Body weight and BMI at all visits for spring water and magnesium bicarbonate (supplemented) spring water groups

\begin{tabular}{|c|c|c|c|c|c|c|c|c|c|}
\hline & \multirow[b]{2}{*}{ Visit } & \multirow[b]{2}{*}{ Day 0} & \multicolumn{2}{|c|}{ Spring Water $(n=33)$} & \multicolumn{5}{|c|}{ Supplemented Spring Water $(n=34)$} \\
\hline & & & Day 14 & Day 42 & Day 84 & Day 0 & Day 14 & Day 42 & Day 84 \\
\hline \multirow[t]{3}{*}{$\begin{array}{l}\text { Weight } \\
(\mathrm{kg})\end{array}$} & Mean (SD) & $\begin{array}{c}67.99 \\
(11.58)\end{array}$ & $\begin{array}{l}68.09 \\
(11.76)\end{array}$ & $\begin{array}{l}68.11 \\
(12.03)\end{array}$ & $\begin{array}{l}67.86 \\
(11.54)\end{array}$ & $\begin{array}{l}64.22 \\
(8.15)\end{array}$ & $\begin{array}{l}64.24 \\
(8.32)\end{array}$ & $\begin{array}{l}64.10 \\
(8.20)\end{array}$ & $\begin{array}{l}64.07 \\
(8.61)\end{array}$ \\
\hline & $\begin{array}{l}\text { Change from baseline (Day 0) } \\
\text { (SD) }\end{array}$ & & $0.02(1.01)$ & $0.03(1.40)$ & $-0.21(1.98)$ & & $0.02(0.78)$ & $-0.12(1.36)$ & $-0.15(1.66)$ \\
\hline & ${ }^{*} P$ value & & & & & 0.126 & 0.921 & 0.749 & 0.946 \\
\hline \multirow[t]{3}{*}{$\begin{array}{l}\mathrm{BMI}(\mathrm{kg} / \\
\mathrm{m} 2)\end{array}$} & Mean (SD) & $25.05(3.64)$ & $25.11(3.71)$ & $25.11(3.78)$ & $25.02(3.59)$ & $\begin{array}{l}24.16 \\
(3.14)\end{array}$ & $\begin{array}{l}24.17 \\
(3.18)\end{array}$ & $\begin{array}{l}24.12 \\
(3.13)\end{array}$ & $\begin{array}{l}24.16 \\
(3.14)\end{array}$ \\
\hline & $\begin{array}{l}\text { Change from baseline (Day 0) } \\
\text { (SD) }\end{array}$ & & $0.010(0.38)$ & $0.009(0.54)$ & $\begin{array}{r}-0.073 \\
(0.76)\end{array}$ & & $\begin{array}{l}0.006 \\
(0.29)\end{array}$ & $\begin{array}{l}-0.048 \\
(0.51)\end{array}$ & $\begin{array}{l}-0.052 \\
(0.62)\end{array}$ \\
\hline & *P value & & & & & 0.289 & 0.991 & 0.681 & 0.930 \\
\hline
\end{tabular}

${ }^{*} p$-value (t-test) comparing groups at Day 0 (italics) and for change from Baseline to Day 14, Day 42 and Day 84

measures (triglycerides, LDL HDL and total cholesterol) (Table 3, Additional file 3) and blood pressure (Table 4, Additional file 4). Measurements of bicarbonate, calcium, creatinine, sodium (Table 5, Additional file 5) and most serum biochemistry also did not show significant differences between the two groups remaining within normal ranges (data not shown). Haematology parameters remained unaltered through study period for both water groups (data not shown).

The concentration of serum PTH increased from Day $0(3.85 \mathrm{pmol} / \mathrm{L})$ to Day $84(4.57 \mathrm{pmol} / \mathrm{L})$ with control water consumption compared to supplemented water for which the concentration remained relatively constant
(4.24 and $4.21 \mathrm{pmol} / \mathrm{L}$, respectively). There was a trend towards a difference in the change in PTH concentration between the two groups from Day 0 to Day 84 (0.74 pmol/L; 95\% Confidence Interval (CI): -0.03 to 1.52 pmol; $\mathrm{p}=0.059$ ) (Figure 1, Table 2). There was no significant difference in the change in PTH concentration between the two groups at Day 0 to Day 14 or Day 42 (see Additional file 2).

The serum concentration of magnesium increased with the intake of the supplemented water compared to that of control water intake $\{0.022 \mathrm{mmol} / \mathrm{L}(95 \% \mathrm{CI}$ : 0.003 to $0.041 \mathrm{mmol} / \mathrm{L}$ ) (Table 5 , Additional file 5). The difference between the two groups in the change

Table 2 Serum bone metabolic markers over the study period for spring water and magnesium bicarbonate (supplemented) spring water groups

\begin{tabular}{|c|c|c|c|c|c|}
\hline & \multirow[b]{2}{*}{ Visit } & \multicolumn{2}{|c|}{ Spring Water $(n=33)$} & \multicolumn{2}{|c|}{ Supplemented Spring Water $(\mathrm{n}=34$} \\
\hline & & Day 0 & Day 84 & Day 0 & Day 84 \\
\hline \multirow[t]{3}{*}{ Parathyroid Hormone (pmol/L) } & Mean (SD) & $3.85(1.79)$ & $4.57(2.14)$ & $4.24(1.74)$ & $4.21(1.96)$ \\
\hline & Change from baseline (Day 0) (SD) & & $0.72(1.52)$ & & $-0.02(1.65)$ \\
\hline & ${ }^{*} \mathrm{P}$ value & & & 0.369 & 0.059 \\
\hline \multirow[t]{3}{*}{ 1,25dihydroxyvitamin $\mathrm{D}$ (pmol/L) } & Mean (SD) & $120.8(40.9)$ & $126.8(40.4)$ & $118.7(39.8)$ & $124.3(40.7)$ \\
\hline & Change from baseline (Day 0) (SD) & & $7.1(49.1)$ & & $5.6(47.9)$ \\
\hline & *P value & & & 0.835 & 0.766 \\
\hline Osteocalcin & Mean (SD) & $13.73(5.44)$ & $14.42(5.88)$ & $15.23(3.89)$ & $13.79(3.48)$ \\
\hline \multirow[t]{2}{*}{$(\mu \mathrm{g} / \mathrm{L})$} & Change from baseline (Day 0) (SD) & $0.70(4.00)$ & $0.07(4.00)$ & & $-1.31(3.89)$ \\
\hline & *P value & & & 0.207 & 0.104 \\
\hline N-telopeptide excretion & Mean (SD) & $36.7(21.7)$ & $40.1(21.3)$ & $34.1(17.8)$ & $35.1(15.7)$ \\
\hline \multirow[t]{2}{*}{$\mathrm{nmol} / \mathrm{mM}(\mathrm{Cr})$} & Change from baseline (Day 0) (SD) & & $3.4(12.66)$ & & $1.0(15.97)$ \\
\hline & ${ }^{*} \mathrm{P}$ value & & & 0.588 & 0.440 \\
\hline \multirow[t]{3}{*}{$\mathrm{OH}$ proline excretion $(\mathrm{nmol} / \mathrm{mM} \mathrm{Cr})$} & Mean (SD) & $15.5(5.39)$ & $17.2(6.75)$ & $15.5(4.98)$ & $15.6(4.57)$ \\
\hline & Change from baseline (Day 0) (SD) & & $1.6(5.98)$ & & $0.1(4.70)$ \\
\hline & ${ }^{*} \mathrm{P}$ value & & & 0.971 & 0.216 \\
\hline
\end{tabular}

*p-value comparing groups at Day 0 (italics) and for change from Day 0 to Day 84 
Table 3 Serum lipid profile over the study period for spring water and magnesium bicarbonate (supplemented) spring water groups

\begin{tabular}{|c|c|c|c|c|c|}
\hline & \multirow[b]{2}{*}{ Visit } & \multicolumn{2}{|c|}{ Spring Water $(\mathrm{n}=33)$} & \multicolumn{2}{|c|}{ Supplemented Spring Water $(n=34$} \\
\hline & & Day 0 & Day 84 & Day 0 & Day 84 \\
\hline Triglyceride & Mean (SD) & $1.12(0.45)$ & $0.95(0.39)$ & $0.95(0.32)$ & $0.92(0.46)$ \\
\hline \multirow[t]{2}{*}{$(\mathrm{mmol} / \mathrm{L})$} & Change from baseline (Day 0) (SD) & & $-0.17(0.46)$ & & $-0.03(0.39)$ \\
\hline & ${ }^{*} P$ value & & & 0.107 & 0.528 \\
\hline Cholesterol & Mean (SD) & $5.79(1.6)$ & $5.69(1.21)$ & $5.44(0.78)$ & $5.51(0.93)$ \\
\hline \multirow[t]{2}{*}{$(\mathrm{mmol} / \mathrm{L})$} & Change from baseline (Day 0) (SD) & & $-0.10(0.63)$ & & $0.07(0.53)$ \\
\hline & ${ }^{*} \mathrm{P}$ value & & & 0.260 & 0.484 \\
\hline High Density Lipoprotein & Mean (SD) & $1.72(0.50)$ & $1.78(0.47)$ & $1.75(0.32)$ & $1.77(0.32)$ \\
\hline \multirow[t]{2}{*}{$(\mathrm{mmol} / \mathrm{L})$} & Change from baseline (Day 0) (SD) & & $0.05(0.19)$ & & $0.02(0.19)$ \\
\hline & ${ }^{*} \mathrm{P}$ value & & & 0.772 & 0.576 \\
\hline \multirow[t]{3}{*}{ Low Density Lipoprotein } & Mean (SD) & $3.57(1.38)$ & $3.48(1.07)$ & $3.31(0.90)$ & $3.33(0.89)$ \\
\hline & Change from baseline (Day 0) (SD) & & $-0.08(0.50)$ & & $0.02(0.38)$ \\
\hline & *P value & & & 0.364 & 0.611 \\
\hline
\end{tabular}

${ }^{*} p$-value comparing groups at Day 0 (italics) and for change from Day 0 to Day 84

from Day 0 to Day 84 in the serum concentrations of magnesium was statistically significant $(\mathrm{p}=0.027)$ (Figure 2, Table 5). When data from all time points were analysed using a repeated measures analysis of variance the difference between groups in the serum concentrations of magnesium remained statistically significant $(p=0.015)$. Serum potassium was also increased by Day 84 with the intake of supplemented water $(\mathrm{p}=0.054)$ (Additional File 5).

Consumption of the supplemented water also significantly increased the urinary $\mathrm{pH}$ at 84 days $(\mathrm{p}=0.0182)$ (Figure 3, Table 4). The venous $\mathrm{pH}$ remained unaltered (Additional file 4) over the study period. There were no other statistically significant differences in change from Day 0 to Day 84 comparing control and supplemented water groups in any of the other 24-hour urinary analytes (data not shown).

\section{Safety Evaluation}

The most common adverse event considered to be related to the water consumption was diarrhoea in five (15.2\%) and eight (23.5\%) subjects in the control and supplemented water groups, respectively. No subject suffered a serious adverse event during this study.

\section{Discussion}

The present study did not show any effect of the consumption of spring water supplemented with magnesium and bicarbonate, as part of a daily routine including usual dietary habits, on clinically relevant

Table 4 Blood pressure (BP) and urinary pH over the study period for spring water and magnesium bicarbonate (supplemented) spring water groups

\begin{tabular}{|c|c|c|c|c|c|}
\hline & \multirow[b]{2}{*}{ Visit } & \multicolumn{2}{|c|}{ Spring Water $(n=33)$} & \multicolumn{2}{|c|}{ Supplemented Spring Water $(n=34)$} \\
\hline & & Day 0 & Day 84 & Day 0 & Day 84 \\
\hline \multirow[t]{3}{*}{ §SUPINE SYSTOLIC BP (mm Hg) } & Mean (SD) & $119.6(13.23)$ & $117.4(10.73)$ & $121.5(13.32)$ & $121.9(14.08)$ \\
\hline & Change from baseline (Day 0) (SD) & & $-2.3(11.64)$ & & $0.4(10.74)$ \\
\hline & *P value & & & 0.562 & 0.1606 \\
\hline \multirow[t]{3}{*}{ §SUPINE DIASTOLIC BP (mm Hg) } & Mean (SD) & $73.1(8.88)$ & $72.0(6.95)$ & $74.1(8.47)$ & $73.9(8.68)$ \\
\hline & Change from baseline (Day 0) (SD) & & $-1.2(7.58)$ & & $-0.2(6.36)$ \\
\hline & *P value & & & 0.650 & 0.367 \\
\hline \multirow[t]{3}{*}{ Urinary pH } & Mean (SD) & $6.13(0.93)$ & $6.17(0.83)$ & $6.38(0.63)$ & $6.66(0.56)$ \\
\hline & Change from baseline (Day 0) (SD) & & $0.05(0.86)$ & & $0.28(0.73)$ \\
\hline & *P value & & & 0.197 & 0.018 \\
\hline
\end{tabular}

*p-value comparing groups at Day 0 (italics) and for change from Day 0 to Day 84

$\S$ Standing systolic and diastolic BP showed no significant difference between two water groups (Data not shown) 
Table 5 Serum electrolytes over the study period for spring water and magnesium bicarbonate (supplemented) spring water groups

\begin{tabular}{|c|c|c|c|c|c|}
\hline & \multirow[b]{2}{*}{ Visit } & \multicolumn{2}{|c|}{ Spring Water $(n=33)$} & \multicolumn{2}{|c|}{ Supplemented Spring Water $(n=34)$} \\
\hline & & Day 0 & Day 84 & Day 0 & Day 84 \\
\hline \multirow[t]{3}{*}{ Bicarbonate $(\mathrm{mmol} / \mathrm{L})$} & Mean (SD) & $27.6(1.84)$ & $27.6(1.60)$ & $27.9(1.94)$ & $27.8(1.93)$ \\
\hline & Change from baseline (Day 0) (SD) & & $0.0(2.01)$ & & $-0.1(1.60)$ \\
\hline & *P value & & & 0.511 & 0.790 \\
\hline \multirow[t]{3}{*}{ Corrected Calcium (mmol/L) } & Mean (SD) & $2.31(0.07)$ & $2.29(0.09)$ & $2.32(0.08)$ & $2.31(0.091)$ \\
\hline & Change from baseline (Day 0) (SD) & & $-0.03(0.07)$ & & $-0.004(0.06)$ \\
\hline & ${ }^{*} P$ value & & & 0.778 & 0.1504 \\
\hline \multirow[t]{3}{*}{ Magnesium (mmol/L) } & Mean (SD) & $0.86(0.06)$ & $0.86(0.06)$ & $0.87(0.05)$ & $0.90(0.052)$ \\
\hline & Change from baseline (Day 0) (SD) & & $0.006(0.04)$ & & $0.03(0.03)$ \\
\hline & ${ }^{*} P$ value & & & 0.320 & 0.006 \\
\hline
\end{tabular}

*p-value comparing groups at Day 0 (italics) and for change from Day 0 to Day 84

bone parameters or cardiovascular indices over a period of 12 weeks.

The bicarbonate component was sufficient to change urinary $\mathrm{pH}$ values, statistically significantly by Day 84 , as an indicator of acid base balance [21]. The blood bicarbonate as an indirect parameter was not different between the groups. Other studies of mineral waters containing bicarbonate at greater concentrations (approximately $1-2 \mathrm{~g} / \mathrm{L})$ than employed here $(650 \mathrm{mg} /$ L) have shown a decrease in bone resorption markers in young women $[22,23]$ and a lowering of markers of atherosclerosis in postmenopausal women $[24,25]$. It is likely that the level of $650 \mathrm{mg} / \mathrm{L}$ bicarbonate in the present study was too low to elicit an effect on bone metabolic and cardiovascular parameters over a short period. In addition, the consumption of a high calcium mineral water has shown that bone modelling parameters were

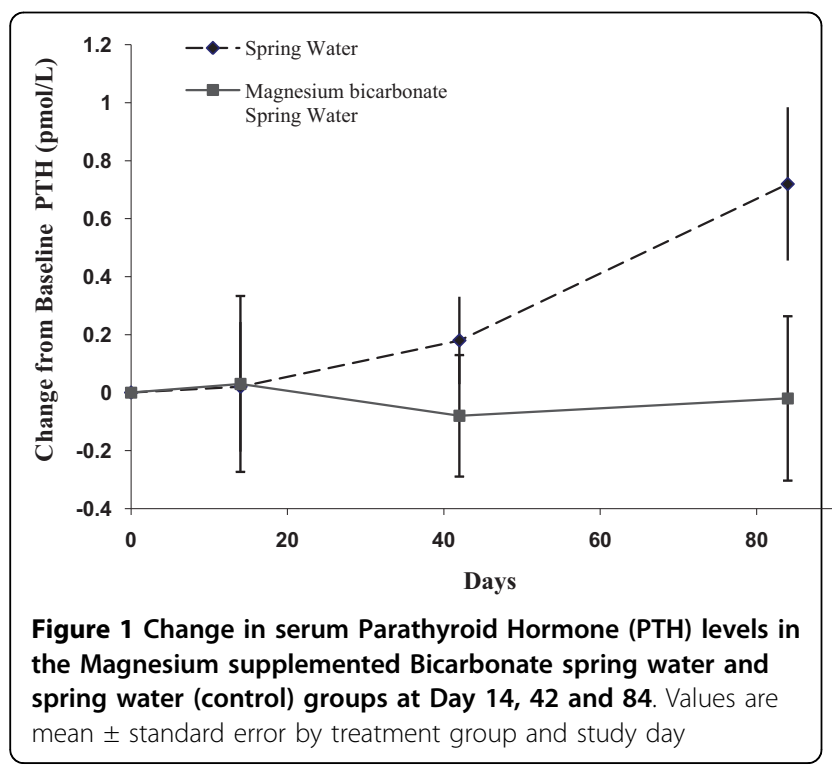

only affected when the study population had low dietary mineral intakes [26].

The present study showed that consumption of magnesium in alkaline aqueous formulation (magnesium bicarbonate supplemented spring water) provided a source of orally available magnesium as evidenced by the increase in serum magnesium concentrations over the 12 weeks of the study period. Other metabolic studies have shown that magnesium mineral waters with magnesium content $(110 \mathrm{mg} / \mathrm{L}$ and $282 \mathrm{mg} / \mathrm{L})$ similar to this study water of $120 \mathrm{mg} / \mathrm{L}$ could be easily absorbed and retained in healthy men and women $[27,28]$. It has been suggested that absorption becomes impaired with increasing age [29], thus the magnesium bicarbonate supplemented spring water could provide a source of magnesium particularly in older women. However, since this study did not measure dietary magnesium intake or excreted magnesium, the absolute contribution of the

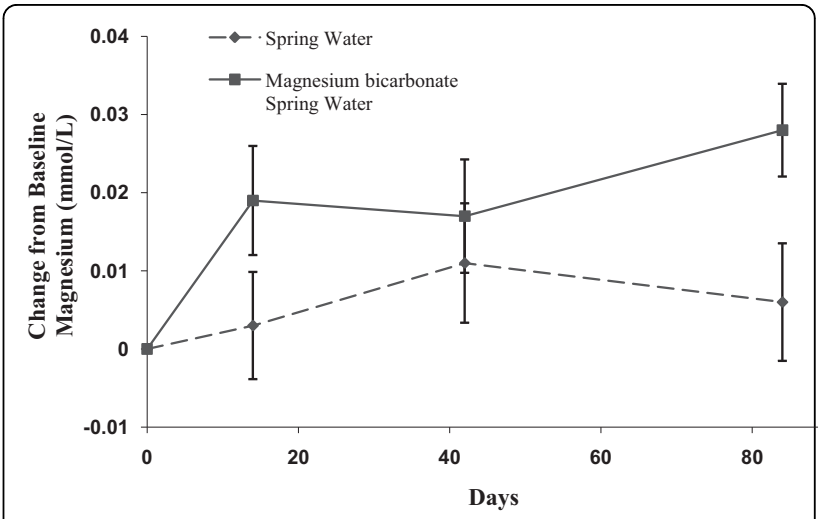

Figure 2 Change in serum Magnesium in the Magnesium Bicarbonate supplemented spring water and spring water (control) groups at Day 14, 42 and $\mathbf{8 4}$. Values are mean \pm standard error by treatment group and study day 


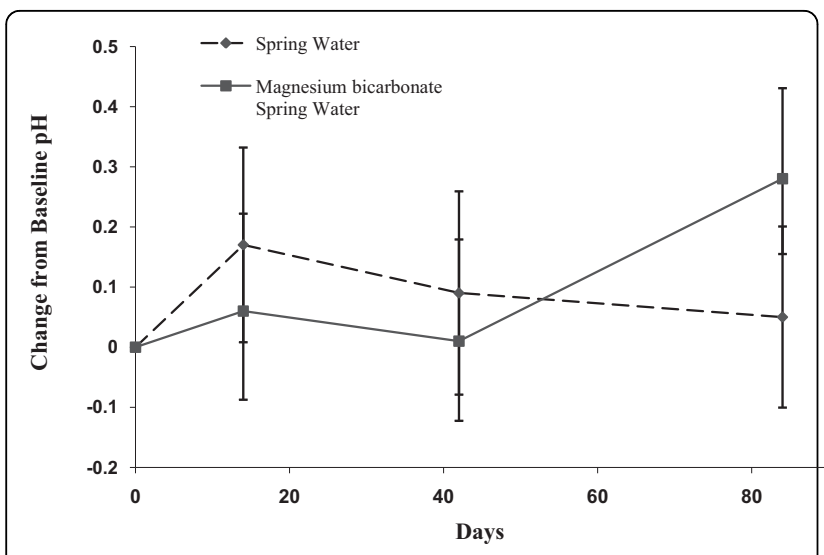

Figure 3 Change in Urinary $\mathrm{pH}$ in Magnesium Bicarbonate supplemented water and spring water (control) groups at Day 14, 42 and $\mathbf{8 4}$. Values are mean \pm standard error by treatment group and study day

magnesium from the supplemented spring water remains unknown.

It is acknowledged that other parameters measured in this study will be influenced by the composition of diet and energy loads. Accordingly the rise in serum potassium by Day 84 with the consumption of the supplemented water remains observational. Thus, despite the requested maintenance of usual dietary habits by all subjects in the study, the lack of dietary records in the study population is a limitation of this exploratory investigation.

In this present study, $\mathrm{PTH}$ concentrations remained stable over 12 weeks in the magnesium bicarbonate water group. This finding is consistent with other studies in normal subjects where intake of oral alkaline [28] and magnesium [30] loads do not alter PTH levels in the short term. It remains to be determined, if the trend to increase in PTH with the consumption of spring water alone becomes sufficient to potentiate the action of PTH on bone metabolism in a clinically meaningful way and if magnesium bicarbonate supplemented spring water has favourable effects on PTH concentrations and bone metabolism with longer-term consumption.

In summary, these results suggest that the consumption of magnesium rich bicarbonate spring water may provide a source of magnesium to contribute to total magnesium intake. Changes in urinary $\mathrm{pH}$ may, in the longer term, lead to improved acid base balance. Longer term studies, that include assessment of diet, urinary volume and mineral excretion, are required to determine the clinical relevance of these findings.

\section{Conclusions}

Short term consumption of magnesium bicarbonate supplemented spring water increased serum magnesium and urinary $\mathrm{pH}$ in postmenopausal women. There was no effect on bone metabolism or cardiovascular risk factors. Whether the former changes are of clinical relevance with respect to various processes, such as those associated with aging which have been linked to magnesium insufficiency and/or acidosis, remains to be determined by further research.

\section{Additional material}

Additional file 1: Analysis of ${ }^{*}$ Spring Water (control). ${ }^{*}$ spring (Peats Ridge) water is commercially registered by the NSW government.

Additional file 2: Serum bone metabolic markers at all visits for two water treatment groups.

Additional file 3: Serum lipid profile at all visits for two water treatment groups.

Additional file 4: Blood pressure (BP) and $\mathrm{pH}$ at all visits for two water treatment groups.

Additional file 5: Serum biochemistry at all visits for two water treatment groups.

\section{Acknowledgements}

To Datapharm Australia Pty Ltd for coordinating and monitoring the clinical study, for data management and statistical analysis, and to Ms Marinella Messina for critical review and contribution to the writing of the manuscript. To the staff of St Vincent's Hospital Clinical Trial Centre for oversight of subject recruitment and care during the study.

\section{Author details}

'St Vincent's Hospital, Clinical Trials Centre, Department of Clinical Pharmacology and Toxicology and University of NSW, Sydney NSW 2010, Australia. ${ }^{2}$ Cancer Care Centre, St George Hospital, Gray St, Kogarah NSW 2217, Australia. ${ }^{3}$ Datapharm Australia Pty Ltd, Drummoyne NSW 2047, Australia. ${ }^{4}$ Unique Global Possibilities Medical Pty Ltd, Sydney NSW 2000, Australia.

\section{Authors' contributions}

ROD developed the study design and plan as well as oversaw the drafting of and was a major contributor to the manuscript. WL participated in the study design, provided input in the clinical study protocol and contributed to the writing of the manuscript. LMRT provided input in the clinical study protocol, provided input into and oversight of the Clinical Study Report, drafted, coordinated and finalised the writing of the manuscript. PM performed the statistical data analysis and provided input into the Clinical Study Report. RJB conceived of the study and contributed to the writing of the manuscript. KMW participated in the study design and contributed to the writing of the manuscript. All authors read and approved the manuscript.

\section{Competing interests}

Dr Beckett is a Director of Unique Global Possibilities Medical Pty Ltd which sponsored the trial. All other authors declare no competing interests.

Received: 29 April 2010 Accepted: 28 June 2010

Published: 28 June 2010

\section{References}

1. Nebrand C, Agreus L, Lenner RA, Nyberg P, Svardsudd: The influence of calcium and magnesium in drinking water and diet on cardiovascular risk factors in individuals living in hard and soft water areas with differences in cardiovascular mortality. BMC Public Health 2003, 3:21.

2. Sauvant MP, Pepin D: Geographic variation of the mortality from cardiovascular disease and drinking water in a French small area (Puy de Dome). Environ Res 2000, 84:219-27. 
3. Marque S, Jacqmin-Gadda H, Dartigues JF, Commenges D: Cardiovascular mortality and calcium and magnesium in drinking water: an ecological study in elderly people. Eur J Epidemio 2003, 18:305-9.

4. Rubenowitz E, Axelsson G, Rylander R: Magnesium and calcium in drinking water and death from acute myocardial infarction in women. Epidemiology 1999, 10:31-6.

5. Rubenowitz E, Molin I, Axelsson G, Rylander R: Magnesium in drinking water in relation to morbidity and mortality from acute myocardial infarction. Epidemiology 2000, 11:416-21.

6. Rubenowitz $E$, Axelsson G, Rylander R: Magnesium in drinking water and death from acute myocardial infarction. Am J Epidemiol 1996, 143:456-62

7. Catling LA, Abubakar I, Lake IR, Swift L, Hunter PR: A systematic review of analytical observational studies investigating the association between cardiovascular disease and drinking water hardness. Water Health 2008, 6:433-42.

8. Rylander R: Drinking water constituents and disease. J Nutr 2008, 138:423S-425.

9. Burckhardt $P$ : The effect of the alkali load of mineral water on bone metabolism: interventional studies. J Nutr 2008, 138:435S-437S.

10. Schoppen S, Pérez-Granados AM, Carbajal A, Oubiña P, Sánchez-Muniz FJ, Gómez-Gerique JA: A sodium-rich carbonated mineral water reduces cardiovascular risk in postmenopausal women. J Nutr 2004, 134:1058-63.

11. Kurtz I, Maher T, Hulter HN, Schambelan M, Sebastian A: Effect of diet on plasma acid-base composition in normal humans. Kidney Int 1983, 24:670-680.

12. Frassetto LA, Morris RC Jr, Sellmeyer DE, Todd K, Sebastian : Diet-evolution and aging. The pathophysiologic effects of the post-agricultural inversion of the potassium-to-sodium and base-to-chloride ratios in the human diet. Eur J Nutr 2001, 40:200-213.

13. Remer T: Influence of nutrition on acid-base balance - metabolic aspects. Eur J Nutr 2001, 40:214-220.

14. Shoback D: Metabolic Bone Disease. Basic \& Clinical Endocrinology New York: McGraw HillGreenspan FS, Gardner DG, Seven 2004, 297-301.

15. Riccardi D: Cell surface, ion-sensing receptors. Exp Physio/ 2002, 87:403-411.

16. Ma J, Folsom AR, Melnick SL, Eckfeldt JH, Sharrett AR, Nabulsi AA Hutchinson RG, Metcalf PA: Associations of serum and dietary magnesium with cardiovascular disease, hypertension, diabetes, insulin and carotid arterial wall thickness: The ARIC Study. J Clin Epidem 1995, 48:927-940.

17. Tucker KL, Hannan MT, Kiel DP: The acid-base hypothesis: diet and bone in the Framingham Osteoporosis Study. Eur J Nutr 2001, 40:231-237.

18. Doyle L, Flynn A, Cashman K: The effect of magnesium supplementation on biochemical markers of bone metabolism or blood pressure in healthy young adult females. Eur J Clin Nutr 1999, 53:255-61.

19. Farvid MS, Siassi F, Jalali M, Hosseini M, Saadat N: The impact of vitamin and/or mineral supplementation on lipid profiles in type 2 diabetes. Diabetes Res Clin Pract 2004, 65:21-28.

20. Jee SH, Miller ER, Guallar E, Singh VK, Appel LJ, Klag MJ: The effect of magnesium supplementation on blood pressure: a meta-analysis of randomized clinical trials. Am J Hypertens 2002, 15:691-696.

21. Welch AA, Mulligan A, Bingham SA, Khaw $K T$ : Urine $\mathrm{pH}$ is an indicator of dietary acid-base load, fruit and vegetables and meat intakes:results from the European Prospective Investigation into Cancer and Nutrition (EPIC)-Norfolk population study. Br J Nutr 2008, 99:1335-43.

22. Wynn E, Krieg MA, Aeschlimann JM, Burckhardt P: Alkaline mineral water lowers bone resorption even in calcium sufficiency: alkaline mineral water and bone metabolism. Bone 2009, 44:120-4.

23. Roux S, Baudoin C, Boute D, Brazier M, De La Guéronniere V, De Vernejoul MC: Biological effects of drinking-water mineral composition on calcium balance and bone remodeling markers. J Nutr Health Aging 2004, 8:380-4.

24. Schoppen S, Pérez-Granados AM, Carbajal A, Sarriá B, Sánchez-Muniz FJ, Gómez-Gerique JA, Pilar Vaquero M: A sodium-rich carbonated mineral water reduces cardiovascular risk in postmenopausal women. J Nutr 2004, 134:1058-6.

25. Schoppen S, Pérez-Granados AM, Carbajal A, de la Piedra C, Pilar Vaquero M: Bone remodelling is not affected by consumption of a sodium-rich carbonated mineral water in healthy postmenopausal women. Br J Nutr 2005, 93:339-44.
26. Meunier PJ, Jenvrin C, Munoz F, de la Gueronnière V, Garnero P, Menz M: Consumption of a high calcium mineral water lowers biochemical indices of bone remodeling in postmenopausal women with low calcium intake. Osteoporos Int 2005, 16:1203-9.

27. Karagülle O, Kleczka T, Vidal C, Candir F, Gundermann G, Külpmann WR, Gehrke A, Gutenbrunner C: Magnesium absorption from mineral waters of different magnesium content in healthy subjects. Forsch Komplementmed 2006, 13:9-14.

28. Verhas $M$, de la Guéronnière V, Grognet JM, Paternot J, Hermanne A, Van den Winkel P, Gheldof R, Martin P, Fantino M, Rayssiguier Y: Magnesium bioavailability from mineral water. A study in adult men. Eur J Clin Nutr 2002, 56:442-7.

29. Dawson-Hughes B, Harris SS, Palermo NJ, Castaneda-Sceppa C, Rasmussen HM, Dallal GE: Treatment with potassium Bicarbonate lowers calcium excretion and bone resorption in older men and women. $J$ Clin Endocrinol Metab 2009, 94:96-102.

30. Doyle L, Flynn A, Cashman K: The effect of magnesium supplementation on biochemical markers of bone metabolism or blood pressure in healthy young adult females. Eur J Clin Nutr 1999, 53:255-61.

doi:10.1186/1756-0500-3-180

Cite this article as: Day et al:: A double-blind, placebo-controlled study of the short term effects of a spring water supplemented with magnesium bicarbonate on acid/base balance, bone metabolism and cardiovascular risk factors in postmenopausal women. BMC Research Notes 2010 3:180.

\section{Submit your next manuscript to BioMed Central and take full advantage of:}

- Convenient online submission

- Thorough peer review

- No space constraints or color figure charges

- Immediate publication on acceptance

- Inclusion in PubMed, CAS, Scopus and Google Scholar

- Research which is freely available for redistribution

Submit your manuscript at www.biomedcentral.com/submit
Biomed Central 